\title{
PEMBINAAN PEMELIHARAAN BANGUNAN DRAINASE BAGI MASYARAKAT DESA SRIKUNCORO KECAMATAN PONDOK KELAPA KABUPATEN BENGKULU TENGAH
}

\section{DRAINAGE BUILDING MAINTENANCE GUIDANCE FOR PEOPLE OF SRIKUNCORO VILLAGE PONDOK KELAPA BENGKULU CENTRAL DISTRICT}

\author{
Oleh: \\ Besperi, Makmun R. Razali dan Samsul Bahri \\ Jurusan Teknik Sipil Fakultas Teknik Universitas Bengkulu \\ besperimt@yahoo.co.id
}

\begin{abstract}
Indonesia has 2 seasons, rainy season and wet season. Normally, it will be flooding in the rainy season in Bengkulu mosely in Central Bengkulu. Flooding happens every year, and this problem does not have the solution yet and the fread shows the increase in frequency, the areas, the depth and the duration. Central Bengkulu has bad drainage. No bad condition of the road, its dishersing the activity of the society. It is imposible to wait for the action from the government to overcome this situation. The society pay great attention from the speech and discusstion about the method to make drainage based on standard.
\end{abstract}

Keywords: Flood, Drainage Contruction, Government and Stakeholders

\section{PENDAHULUAN}

Indonesia merupakan daerah yang mengalami 2 musim yaitu musim hujan dan musim kemarau. Pada musim hujan termasuk Bengkulu lebih khusus lagi Kabupaten Bengkulu Tengah (Benteng) mengakibatkan sering mengalami bencana banjir. Peristiwa ini hampir setiap tahun berulang, sampai saat ini belum terselesaikan bahkan cenderung makin meningkat baik frekuensinya, luasannya, kedalamannya, maupun durasinya. Daerah aliran sungai (DAS) Bengkulu merupakan salah satu sungai utama yang berada di wilayah Provinsi Bengkulu. Sungai Air Bengkulu termasuk dalam satuan wilayah pengelolaan LemauBengkulu yang memegang peranan penting dalam penyediaan air baik untuk kebutuhan irigasi, pertanian, perikanan, maupun air baku bagi masyarakat Bengkulu. Secara geografis DAS Air Bengkulu terletak antara 03 58' 00' ' LS - 03 ${ }^{\circ} 85^{\prime} 00^{\prime}$ ' LS dan $102^{\circ} 23^{\prime}$ BT - $102^{\circ}$ 60' BT (BP DAS Ketahun, 2010). Daerah aliran sungai (DAS) Air Bengkulu seluas 51.500,01 Ha ini berada pada dua kabupaten/kota yaitu Kabupaten Bengkulu Tengah di hulu dan bermuara di hilir Kota Bengkulu (Indarti, 2011). Bengkulu Tengah merupakan hulu dari DAS perlu diperhatikan pengaliran drainasenya supaya pengaliran untuk daerah hilirnya berjalan dengan baik nantinya. Kabupaten Bengkulu Tengah (Benteng) definitif sebagai kabupaten termuda di Propinsi Bengkulu sejak tanggal 19 November 2008, yang terpisah dari kabupaten induknya yaitu kabupaten Bengkulu Utara. Sebagai kabupaten pemekaran 
yang baru, geliat pembangunan sudah mulai nampak, walaupun dengan segala keterbatasan yang dimilikinya. Kecamatan Pondok Kelapa memiliki beberapa desa yang tersebar di beberapa wilayah dengan letak geografis yang beragam. Ada desa yang wilayahnya datar, berbukit dan kombinasi keduanya (Bahri 2011). Masalah yang dihadapi oleh masyarakat di desa adalah buruknya infrastruktur Bangunan Drainase. Dari kondisi jalan yang berlobang dan drainasenya kurangmemadai, Ini menjadikan aktivitas masyarakat menjadi terganggu. Menunggu perbaikan bangunan drainase dari pemerintah daerah dalam situasi sekarang ini, tidak bisa berharap banyak mengingat dana yang dimiliki oleh Pemda Benteng pada tahuntahun ini difokuskan untuk pembangunan gedung dan prasarana pemerintahan daerah yang dirasa lebih mendesak. Atas dasar itu maka Tim pengabdian Universitas Bengkulu berinisiatif untuk memberikan pembinaan pemeliharaan bangunan drainase kepada Masyarakat. Pada saat ini, masyarakat Benteng belum memiliki pengetahuan dan kesadaran yang cukup dalam memelihara bangunan drainase yang ada. Di samping itu masyarakat belum memahami manfaat pemeliharaan bangunan drainase terhadap terciptanya lingkungan yang sehat dan sekaligus mengurangi kerusakan fasilitas yang lain. Oleh karena itu, diperlukan pelatihan dan pembinaan tentang teknik pemeliharaan bangunan drainase, pengaruhnya terhadap terwujudnya lingkungan yang sehat, dan dampak bangunan drainase yang tidak terpelihara terhadap kerusakan fasilitas-fasilitas lainnya. Perubahan yang diharapkan dari pelatihan adalah perubahan pengetahuan, keterampilan dan sikap. Penyampaian materi kegiatan ini dilakukan melalui ceramah yang dilengkapi contoh-contoh yang berhubungan dengan materi pelatihan untuk memotivasi peserta agar bertanya dan berdiskusi. Selain ceramah diperlukan praktek langsung bagaimana cara memelihara banguan drainase yang benar sehingga masyarakat dapat melakukan pemeliharaan seluruh bangunan-bangunan drainase dikemudian hari. Berdasarkan analisis situasi dan pengamatan pendahuluan, maka permasalahan yang dapat diidentifikasi adalah: Masyarakat Bengkulu Tengah belum memiliki pengetahuan yang cukup dalam pemeliharaan bangunan drainase, Masyarakat Bengkulu Tengah belum mengetahui cara memelihara bangunan drainase yang baik, Masyarakat Bengkulu Tengah belum memahami dampak bangunan drainase yang tidak baik terhadap kerusakan fasilitas-fasilitas lainnya. Masyarakat di Bengkulu Tengah belum mengenal baik pemeliharaan banguan drainase dan dampaknya terhadap lingkungan terutama kerusakan fasilitas lainnya dan kesehatan lingkungan. Oleh karena itu, Tim Pengabdian Kepada Masyarakat Universitas Bengkulu mempunyai tanggung jawab untuk membantu memecahkan masalah yang ada di lapangan dengan cara memberikan pelatihan, pembinaan dalam pemeliharaan bangunan drainase kepada masyarakat desa srikuncoro Kecamatan pondok kelapa Kabupaten Bengkulu Tengah. Disamping itu Tim Pengabdian Kepada Masyarakat Universitas Bengkulu akan melakukan pembinaan, pelayanan konsultasi terpadu mengenai pemeliharaan bangunan drainase secara berkelanjutan. Pada akhirnya kegiatan ini akan secara nyata memberikan kontribusi positif kepada peningkatan kesadaran masyarakat dalam menciptakan Benteng sebagai kota wisata yang sehat. Drainase berasal dari bahasa Inggris drainage yang mempunyai arti mengalirkan, menguras, membuang atau mengalirkan air. Dalam bidang teknik Sipil drainase secara umum dapat 
didefinisikan sebagai suatu tindakan teknis untuk mengurangi kelebihan air, baik yang berasal dari air hujan, rembesan maupun kelebihan air irigasi dari satu kawasan/lahan sehingga fungsi kawasan atau lahan tidak terganggu. Drainase dapat juga diartikan sebagai usaha untuk mengontrol kualitas air tanah dalam kaitannya dengan salinitas. Jadi drainase menyangkut tidak hanya air permukaan tapi juga air tanah. Kecenderungan dalam pembangunan bangunan drainase selama ini kurang melibatkan masyarakat secara aktif. Oleh karena itu mulai sekarang harus melibatkan masyarakat baik itu yang berupa non fisik maupun pembangunan fisik sejak awal munculnya ide sampai dengan pengoperasiannya (Suripin, 2003). Dalam pembangunan bangunan drainase perlu adanya koordinasi dengan komponen infrastruktur yang lain sehingga tidak terulang lagi dijumpai tiang listrik ditengah saluran drainase dan pipa air bersih (PDAM) memotong saluran pada penampang basahnya. Sering juga dihadapi penggalian saluran drainase dengan tak sengaja merusak tanaman yang ada. Pembuatan saluran derainase yang harus diperhatikan berbagai faktor diantaranya: Kemiringan talud, Bentuk penampang, Jenis pasangan, Aliran, Perbandingan kedalaman air dengan lebar dasar (h:b): Kemiringan talud saluran jenis tanah lempung pasiran,Tanah pasiran kohesif yaitu 1,5-2,5, Tanah pasir lanauan 2-3, Jenis batu <0,25, Bentuk penampang melintang saluran. Untuk mengalirkan air dengan penampang sekecil mungkin bentuk penampang basah yang paling baik adalah bentuk setengah lingkaran. Dalam praktek bentuk ini sulit dibangun sehingga bentuk yang lazim digunakan yaitu bentuk trapesium (Besperi, 2013). Saluran drainase yang umum digunakan dan lebih ekonamis adalah saluran tanpa pasangan tetapi untuk bangunan dipakai bangunan dengan pasangan baik bangunan goronggorong dan bangunan terjunan.Untuk mendesain saluran drainase tanpa pasangan maka aliran dianggap aliran tetap. Perbandingan kedalaman dengan lebar dasar ekonamis berkisar antara 1,1, 5,2, 2,5, 3,3, 5,4 dan 4,5. Begitu juga dalam pembuatan bangunan drainase lebar bangunan gorong-gorong dan bangunan terjun sebaiknya lebarnya sama dengan dimensi saluran drainase. Dalam perencanaan drainase bangunan terjun tipe yang digunakan sebaiknya bangunan tipe bangunan terjun miring (Mawardi, 2010). Pemeliharaan drainase adalah usaha-usaha untuk menjaga agar prasarana drainase selalu berfungsi dengan baik selama mungkin, selama jangka waktu pelayanan yang direncanakan. Ruang pemeliharaan sistim derainase meliputi: Kegiatan pengamanan pencegahan, kegiatan perawatan,kegiatan perbaikan (Suripin, 2003). Tujuan dari kegiatan ini adalah: (1) Meningkatkan pengetahuan dan keterampilan masyarakat mengenai teknik pemeliharaan bangunan drainase, (2) Meningkatkan pengetahuan masyarakat mengenai pemeliharan bangunan drainase yang baik terhadap kemajuaan perkembangan desa, dan (3) Meningkatkan pemahaman masyarakat tentang dampak pembangunan bangunan drainase yang kurang baik terhadap kerusakan fasilitas lainnya.

\section{METODE PENGABDIAN}

Metode yang digunakan dalam perencanaan Bangunan drainase pada aparat desa dan masyarakat Srikuncoro adalah ceramah dan diskusi tentang metode pembuatan Bangunan- 
bangunan drainase yang memenuhi standar kontruksi dan tentang pemiliharan kontruksi drainase. Untuk mencapai tujuan kegiatan, langkah-langkah yang diambil menyiapkan materi pemeliharaan bangunan drainase kepada masyarakat dan aparat desa. Institusi yang terkait dalam kegiatan ini antara lain adalah masyarakat beserta aparat desa Srikuncoro, mahasiswa teknik sipil Universitas Bengkulu. Evaluasi dilakukan pada setiap tahapan dalam bentuk: Kemampuan khalayak sasaran dalam menyerap pengetahuan yang telah diberikan, dievaluasi dalam bentuk tanya jawab dan diskusi dan hasil pelatihan dan pembinaan pemeliharaan bangunan drainase masyarakat dan aparat desa mampu memelihara seluruh bangunan-bangunan drainase yang ada secara berkelanjutan.

\section{HASIL DAN PEMBAHASAN}

Sebagai Dosen harus memenuhi kewajiban Tridarma perguruan tinggi sebagi pendidik, melakukan penelitian, dan melakukan pengabdian kepada masyarakat. Pengabdian kepada masyarakat dilakukan pada hari kamis malam jum'at tanggal 4 September 2014 jam 20.00 s/d selesai di Dusun 2 desa Srikuncoro Kecamatan Pondok Kelapa Benglulu Tengah. Kegiatan ini bertema penyuluhan dan pembinaan pemeliharaan bangunan drainase bagi masyarakat Srikuncoro Kecamatan Pondok Kelapa Kabupaten Bengkulu Tengah. Adapun peserta yang mengikuti kegiatan ini adalah Masyakat Srikuncoro beserta aparat desa. Pada pelaksanaan pengabdian pertama mempersentasikan mengenai kondisi penyebab banjir di dunia dan di Indonesia kemudian menjelaskan bangunan drainase baik cara membuat, memelihara dan kegunaan bagi masyarakat. Masuk materi peserta sangat antusias karena mengenai bangunan drainasie sangat berhubungan erat dengan kondisi dimasyarakat tersebut. Pada presentasi makalah banyak peserta yang antusias bertanya baik masalah bentuk, ukuran cara pembuatan dan pemeliharaannya. Sebagai contoh pertanyaan Bagaimana cara membuat bangunan-bangunan drainasi?, Bentuk Saluran yang pas digunakan seperti apa?. Untuk jalan raya kampung berapa ukuran dimensi bangunan goronggorong dan bangunan-bangunan yang lainnya?, kalau terjadi banjir bagaimana cara membuang airnya supaya tetap dapat melaksanakan pekerjaannya?, Kami dekat laut dan daerah gambut bagaimana cara memeliharanya?. Pertanyaan-pertanyaan dari masyarakat tersebut kami sesama dosen saling bantu dalam menjawab pertanyaan/ kebutuhan mereka. Dari beberapa pertanyaan diatas diberikan beberapa jawaban: Cara membuat Banguanbangunan drainase harus dilihat debit yang tersedia dengan melakukan pengukuran kecepatan menggunakan pelampung kecil kemudian diletakan didalam aliran. Aliran mengalir dari tempat yang tinggi ke tempat yang rendah dicatat waktunya, kemudian diukur dimensinya maka didapat debitnya. Dari debit itulah baru bias membuat tipe bangunanbangunan yang sesuai. Bentuk Salurannya yang paling ideal digunakan bentuk setengah lingkaran. Hanya dalam perakteknya pelaksanaan sulit diterapkan baik pembuatan malnya maupun pekerjaannya. Untuk di Desa Srikucoro untuk saluran bentuk segiempat. Pembuatan banguan terjun digunakan terjun miring karena daerahnya tidak terlalu curam. Goronggorong yang sesuai dikerkaan sesiai dengan ukuran dimensi saluran yang ada. Saluran untuk 
jalan raya tergantung curah hujan yang ada dan lama limpasannya Kalau terjadi banjir dilakukan pembuatan bangunan pelimpah. Dalam pembuatan bangunan - bangunan bagian hilir dibuat pintu sorong atau scot balak untuk pengaturan muka air. Diskusi-diskusi yang dilaksanakan sangat menarik karena pertanyaan-pertanyaan membutuhkan penjelasan detail karena penjelasannya dilakukan dengan memberi contoh yang mudah dimengerti oleh masyarakat. Penjelasan sampai sekecil-kecilnya dibahas untuk memahami semua peserta.
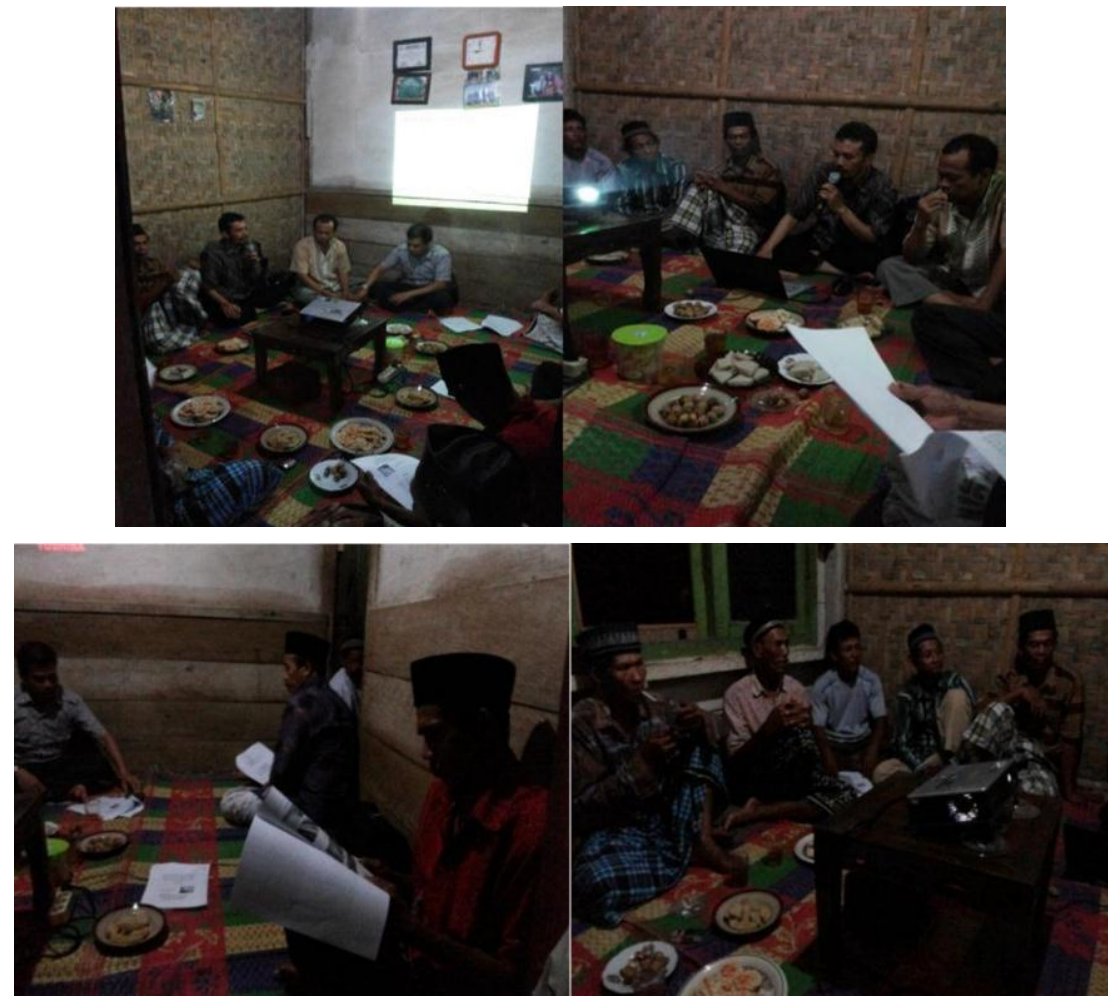

\section{KESIMPULAN DAN SARAN}

\section{Kesimpulan}

Memperhatikan hasil kegiatan yang diperoleh serta hasil evaluasi pada pengabdian penyuluhan sistem drainase dapat disimpulkan: Masyarakat dan aparat desa mengikuti penyuluhan sangat antusias, mengerti dan mampu melaksanakan pekerjaan dan pemeliharaan bangunan-bangunan derainase. Peserta merasakan manfaat dari penyuluhan ini terut ama dalam pembuatan dan pemeliharaan bangunan-bangunan derainase. Peserta memahami pentingnya bangunan-bangunan drainase setiap pekerjaan kontruksi.

\section{Saran}

Adapun saran Bagi Aparat Desa dan masyarakat sebaiknya melaksanakan apa-apa yang telah dilakukan tim pengabdian mengenai teknik pembuatan dan pemeliharaan bangunan-bangunan drainase. Dari hasil yang telah dilakukan perlu dilakukan pengabdian lebih lanjut. 


\section{DAFTAR PUSTAKA}

Besperi, dkk, 2013, Penyuluhan tentang Sisten Saluran Drainase bagi Pekerja Konstruksi. Mawardi, 2010, Desain Hidraulik Bangunan Irigasi, Alfabeta, Bandung.

Bahri, Samsul, dkk, 2011. Pelatihan Merencana dan Menyusun Anggaran Biaya Infrastruktur Jalan bagi Masyarakat Desa Srikuncoro Kecamatan Pondok Kelapa Kabupaten Bengkulu Tengah, Bengkulu.

Soeprapto, 2000, Bahan dan Struktur Jalan, Biro Penerbit, Yogyakarta.

Suripin, 2003, Sistem Drainase Perkotaan yang Berkelanjutan, Andi, Semarang.

Indarti, Yosi, 2011, Analisa Curah Hujan untuk Pendugaan Debit Puncak dengan Metode Melchior pada Sub-Das Bengkulu Hilir Sungai Air Bengkulu, Skripsi Jurusan Teknik Sipil Universitas Bengkulu. 